06

\title{
Исследование влияния обработки лазерными импульсами наносекундной длительности на структуру субмикрокристаллического титана
}

\author{
(С Ю.Р. Колобов ${ }^{1,2}$, С.С. Манохин ${ }^{1,2}$, Г.В. Одинцова ${ }^{3}$, В.И. Бетехтин ${ }^{2}$, А.Г. Кадомцев ${ }^{2}$, М.В. Нарыкова ${ }^{2}$ \\ ${ }^{1}$ Институт проблем химической физики РАН, Черноголовка, Московская обл., Россия \\ ${ }^{2}$ Физико-технический институт им. А.Ф. Иофрфе РАН, Санкт-Петербург, Россия \\ ${ }^{3}$ Университет ИТМО, Санкт-Петербург, Россия \\ E-mail: kolobov@icp.ac.ru
}

Поступило в Редакцию 5 марта 2021 г.

В окончательной редакции 13 апреля 2021 r.

Принято к публикации 13 апреля 2021 г.

Методами растровой и просвечивающей электронной микроскопии (с возможностью микрорентгеноспектрального анализа) проведено исследование микроструктуры тонкого (толщиной $1-2 \mu \mathrm{m})$ подповерхностного слоя образцов титанового сплава ВТ1-0 в исходном субмикрокристаллическом состоянии после воздействия лазерными импульсами наносекундной длительности.

Ключевые слова: титан, поверхность, наносекундное лазерное облучение, ударно-волновое воздействие.

DOI: 10.21883/PJTF.2021.14.51182.18754

В последнее десятилетие активно развиваются исследования и проводится освоение на практике субмикрокристаллического (СМК) и наноструктурного (НС) нелегированного титана, применение которого в качестве материала для медицинских изделий в травматологии, ортопедии и стоматологии постоянно расширяется [1-3]. СМК-титан в отличие от широко используемого для изготовления костных имплантатов сплава Ti-6Al-4V (сплав ВТ6) не содержит вредных для живого организма легирующих элементов: ванадия и алюминия. Несмотря на это, данный сплав в СМК-состоянии не уступает многим легированным титановым сплавам по уровню прочности при статическом и циклическом нагружении и проявляет значительно более высокую пластичность при испытаниях на изгиб и кручение $[1,2]$. К настоящему времени разработаны малозатратные и высокопроизводительные методы воздействия пластической деформацией в сочетании с известными способами механико-термической обработки для формирования СМК- и НС-состояний в нелегированном титане $[1,2]$.

Одним из перспективных направлений в области создания новых технологий обработки металлических материалов медицинского назначения является поверхностная модификация с использованием концентрированных потоков энергии $[1,2,4]$. Подавляющее большинство широко применяющихся в производственной практике способов модификации поверхностей материалов связано со значительным разогревом подповерхностных слоев или всего объема изделия. Вследствие этого интенсивно развиваются процессы возврата и рекристаллизации в областях, подвергнутых разогреву. Данные процессы приводят к необратимой утрате эффектов упрочнения, связанных с наличием НС- и СМК-структур $[2,5,6]$. В значительной степени избежать этого позволяет активно развиваемый в послед- нее десятилетие перспективный метод обработки поверхностей металлических материалов лазерными импульсами короткой (пико-, нано- и субнаносекундной) и ультракороткой (субпико- и фемтосекундной) длительности [2,4]. Развивающиеся при таком воздействии процессы, связанные с изменением рельефа поверхности и фазово-структурными превращениями в тонких подповерхностных (толщиной $1-5 \mu \mathrm{m}$ ) слоях, позволяют формировать уникальный комплекс физико-химических и механических свойств указанных областей материалов. Варьируя параметры лазерного излучения, можно контролируемым образом изменять рельеф поверхности от макро- до наноуровня, в том числе создавая многомодальную шероховатость, с которой связано проявление супергидрофобных или супергидрофильных свойств поверхности. Известно, что переход от режима абляции материала поверхности к режиму ударно-волной обработки (лазерная ковка, peening) позволяет улучшать механические характеристики как подповерхностных, так и приповерхностных слоев материалов до глубины в несколько сотен микрометров [2,7].

В связи с изложенным выше целью настоящей работы является исследование изменения исходной субмикрокристаллической структуры подповерхностного слоя технически чистого титана при воздействии лазерными импульсами наносекундной длительности.

В качестве материала для исследований выбран технически чистый титан марки ВТ1-0, химический состав которого приведен в таблице.

Образцы для исследований изготавливались из прутков сплава ВТ1-0 ( $\alpha$-титан с ГПУ-модификацией кристаллической решетки) диаметром $8 \mathrm{~mm}$, полученных с использованием продольной, поперечно-винтовой и сортовой прокаток (ТУ 1825-001-02079230-2009), которые подвергались финишному отжигу при температуре 
Химический состав сплава ВТ1-0 (на основе Тi)

\begin{tabular}{c|c|c|c|c|c|c|c} 
& \multicolumn{7}{|c}{ Содержание элементов, wt.\% } \\
\cline { 2 - 7 } & $\mathrm{Al}$ & $\mathrm{Fe}$ & $\mathrm{Si}$ & $\mathrm{O}$ & $\mathrm{C}$ & $\mathrm{N}$ & $\mathrm{H}$ \\
\cline { 2 - 8 } \\
\cline { 2 - 8 } \\
Требование
\end{tabular}

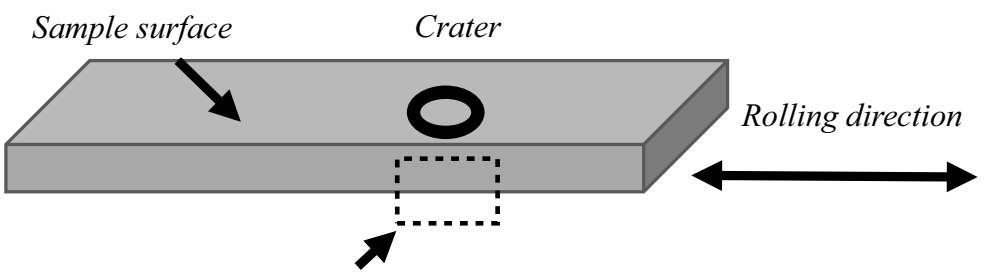

Cutting plane parallel

to the rolling direction

$a$

$b$

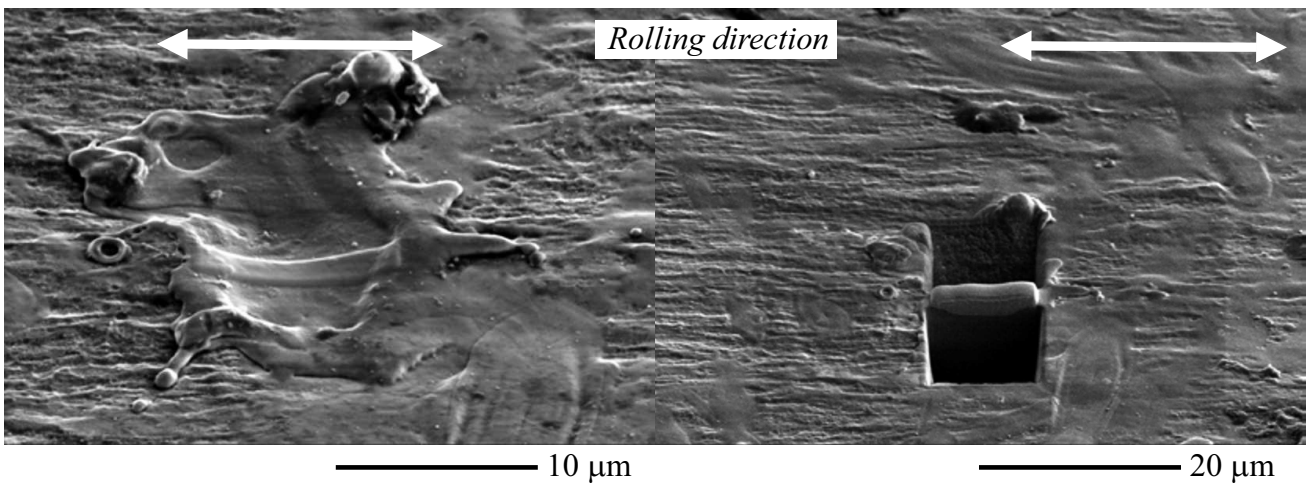

Рис. 1. Структура исходного кратера с нанесенным защитным покрытием слоя платины $(a)$, заготовка тонкой фольги $(b)$. Сверху показана схема подготовки образцов для ПЭМ-исследований.

$673 \mathrm{~K}$ в течение 10800 s для снятия внутренних напряжений первого рода [1].

Структурные исследования проводились на просвечивающих электронных микроскопах (ПЭМ) Тесnаi G2 F20 S-TWIN, FEI TecnaiOsiris при ускоряющем напряжении $200 \mathrm{kV}$. Подготовка вырезаемых перпендикулярно поверхности образца тонких фольг (ламелей) для ПЭМ осуществлялась методом ионного утонения сфокусированным ионным пучком в колонне растрового электронно-ионного микроскопа FEI Scios (PЭМ).

Лазерная обработка образцов под слоем воды толщиной порядка $2 \mathrm{~mm}$ проводилась на установке „Минимаркер-2“ со следующими параметрами облучения: длина волны $\lambda=1064 \mathrm{~nm}$, длительность импульса $\tau \sim 100 \mathrm{~ns}$, энергия в импульсе $E \sim 2 \cdot 10^{-3} \mathrm{~J}$, частота следования импульсов $v=50 \mathrm{kHz}$, скорость сканирования лазерного пучка $v=1500 \mathrm{~mm} / \mathrm{s}$, плотность мощности энергии излучения $F=2 \mathrm{GW} / \mathrm{cm}^{2}$. При указанной скорости сканирования на поверхности материала (под слоем воды) можно наблюдать как отдельные, так и перекрывающиеся кратеры.

Для приготовления тонкой фольги (ламели) из подповерхностного слоя исследуемого материала методом „cross-section“ использовался растровый электронноионный микроскоп FEI Scios Dual Beam (ЦКП ФНИЦ „Кристаллография и фотоника“). Метод „сross-section“ заключается в приготовлении и просмотре шлифов поперечного среза исследуемого образца непосредственно в камере растрового электронно-ионного микроскопа, позволяет исследовать детали внутренней структуры $[8,9]$. Дальнейшее утонение ионным пучком отрезанных образцов в форме тонких параллелепипедов позволяет приготовить тонкие фольги (ламели) для исследования в ПЭМ. Искажения (дефекты), вносимые при такой подготовке, как известно из литературы, минимальны в сравнении с имеющими место при других методах подготовки образцов для ПЭМ [10,11]. Ламели вырезались из середины отдельно расположенных кратеров в виде расплывшейся капли расплава, образовавшихся при воздействии одиночного импульса. По периферии таких кратеров отчетливо наблюдается выпуклый валик с овальными краями, дополнительно свидетельствующий о локальном плавлении.

Тонкая фольга (ламель) готовилась в сечении, нормаль к которому перпендикулярна направлению прокатки и поверхности вырезанного образца в форме тонкого параллелепипеда (рис. 1). 

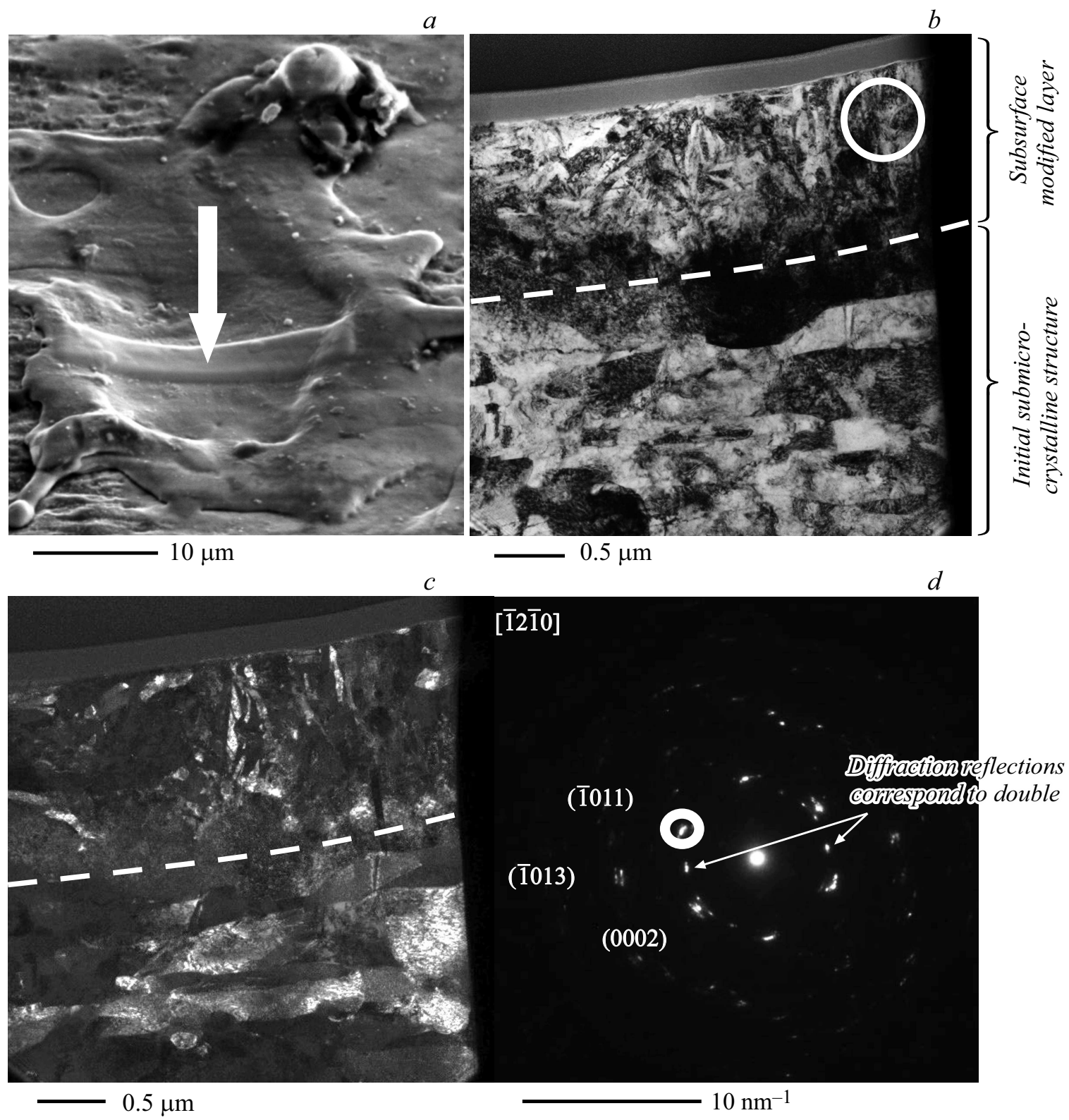

Рис. 2. $a$ - структура поверхности образца сплава ВТ1-0 в области кратера (РЭМ), из середины которого (показано стрелкой) вырезана тонкая фольга (ламель). $b$ - микроструктура подповерхностного слоя в поперечном сечении (ПЭМ). Окружностью выделена область получения микродифракционной картины. $c$ - темнопольное изображение того же участка ламели. $d-$ микродифракция с указанием индексов Миллера. Кружком отмечен рефлекс (1011), в котором получено темнопольное изображение (ПЭМ).

При изготовлении образца использовалось защитное покрытие на основе платины. Это необходимо для получения ровного поперечного среза. После напыления защитного покрытия в образце вблизи напыленной полосы платины ионным пучком вытравливалась область глубиной до $10 \mu \mathrm{m}$ вдоль рабочей плоскости среза.

В исходном субмикрокристаллическом состоянии структура сплава ВТ1-0, подробно описанная в $[1,2]$, характеризуется основной долей элементов зеренносубзеренной структуры в интервале размеров $0.1-1 \mu \mathrm{m}$, а доля зерен размером $100 \mathrm{~nm}$ и менее состав- ляет $\sim 15 \%$ при среднем размере элементов зеренносубзеренной структуры $190 \pm 10 \mathrm{~nm}[1,2,6]$.

Из рис. 2,c видно, что вблизи поверхности (в выделенном штриховой линией тонком подповерхностном слое толщиной порядка $2 \mu \mathrm{m}$ ) после лазерного воздействия сформировалась микроструктура в виде кристаллитов удлиненной пластинчатой формы шириной порядка $100 \mathrm{~nm}$ и длиной $0.5-1 \mu \mathrm{m}$.

Кристаллиты вытянуты преимущественно в направлении, перпендикулярном поверхности образца, как это и должно быть при кристаллизации с теплоотводом в 
этом направлении. Расположение рефлексов не соответствует двойниковой разориентации [12]. Согласно [12], при двойниковании в такой ориентации кристаллита наблюдались бы двойниковые рефлексы зеркально симметрично плоскости типа $\{\overline{1} 011\}$. Таким образом, близкорасположенные рефлексы от плоскостей типа $\{10 \overline{1} 1\}$, $\{0002\},\{10 \overline{1} 0\}$ и других свидетельствуют о наличии малоугловых границ между соседними кристаллитами. Рефлекс, отмеченный стрелкой на рис. $2, d$, индицируется как образовавшийся вследствие двойной дифракции от плоскости (1013), вероятно, по причине наличия двух слоев кристаллитов в объеме образца.

Можно предположить, что такая разориентация кристаллитов связана с их зарождением из расплава на кристаллической подложке с отчетливо выраженной кристаллической текстурой, характерной для СМК-титана, полученного прокаткой. Диффузное размытие рефлексов на картине микродифракции свидетельствует о наличии микронапряжений в кристаллической решетке элементов микроструктуры.

Микроструктура приповерхностного слоя образца на глубине более $2 \mu \mathrm{m}$ (область, расположенная ниже подповерхностного слоя (под штриховой линией) на pис. $2, b, c)$ представляет собой вытянутые вдоль направления прокатки (на стадии формирования СМК-структуры) параллельно поверхности фольги элементы исходной (до лазерного облучения) зеренно-субзеренной структуры. Ортогональное расположение направлений вытянутости образовавшихся в процессе лазерного воздействия элементов микроструктуры в тонком подповерхностном слое и расположенных на больших глубинах (на всю толщину образцов) элементов исходной СМК-структуры позволяет сделать однозначное заключение о глубине качественного изменения микроструктуры.

Установлено, что после воздействия одиночным лазерным импульсом наносекундной длительности под слоем воды в исходной СМК-структуре формируется модифицированный подповерхностный слой толщиной порядка $1-2 \mu \mathrm{m}$.

Полученные данные могут быть использованы в качестве методического приема при определении толщин тонких модифицированных при лазерной обработке подповерхностных слоев металлов и сплавов в исходном субмикрокристаллическом или другом постдеформационном состоянии. Экспериментально измеренные значения толщин расплавленных при воздействии лазерных импульсов подповерхностных слоев могут быть сопоставлены с их теоретическими оценками. Это дает возможность корректировки таких оценок, необходимых для разработки методов модификации тонких приповерхностных слоев для улучшения комплекса механических и других свойств листового проката металлов и сплавов.

Таким образом, установлено, что в тонком (толщиной порядка $1-2 \mu \mathrm{m})$ подповерхностном слое образцов исходного субмикрокристаллического титана после воздействия наносекундным лазерным импульсом вместо исходной СМК-структуры с вытянутыми вдоль направления прокатки зернами формируется пластинчатая микроструктура с вытянутыми (преимущественно перпендикулярно поверхности образца) элементами микроструктуры с поперечным размером порядка $100 \mathrm{~nm}$ и длиной $0.5-1.0 \mu \mathrm{m}$. Изменения микроструктуры в подповерхностном слое в областях вблизи центральной части кратера свидетельствуют о процессах направленной перпендикулярно поверхности образца кристаллизации расплавленного лазерным пучком тонкого подповерхностного слоя.

\section{Благодарности}

Экспериментальные исследования проводились с использованием научного оборудования ЦКП ФНИЦ „Кристаллография и фотоника“ РАН (Москва).

\section{Финансирование работы}

Работа в основной части, связанной с исследованием субмикрокристаллической структуры сплава ВТ1-0 после наносекундного лазерного воздействия, поддержана Российским научным фондом (проект № 19-12-00221), в дополнительной части, связанной с определением параметров рельефа поверхности, в том числе геометрических размеров одиночных кратеров на поверхности образцов исследуемого сплава, выполнена при финансовой поддержке государственного задания (номер госрегистрации AАAА-A19-119100800130-0).

\section{Конфликт интересов}

Авторы заявляют, что у них нет конфликта интересов.

\section{Список литературы}

[1] Ю.Р. Колобов, Рос. нанотехнологии, 4 (11-12), 69 (2009). [Пер. версия: https://doi.org/10.1134/S1995078009110020].

[2] Ю.Р. Колобов, Изв. вузов. Физика, 61 (4), 11 (2018). [Пер. версия: 10.1007/s11182-018-1440-4].

[3] R.Z. Valiev, A.P. Zhilyaev, T.G. Langdon, Bulk nanostructured materials: fundumentals and application (John Wiley and Sons, Inc., Hoboken, USA) (2013). DOI: $10.1002 / 9781118742679$

[4] А.А. Ионин, С.И. Кудряшов, А.А. Самохин, УФН, 187 (4), 159 (2017). DOI: 10.3367/UFNr.2016.09.037974 [Пер. версия: 10.3367/UFNe.2016.09.037974].

[5] M. Hoseini, M.H. Pourian, F. Bridier, H. Vali, J.A. Szpunar, P. Bocher, Mater. Sci. Eng. A, 532, 58 (2012). DOI: $10.1016 /$ j.msea.2011.10.062

[6] V.N. Perevezentsev, A.S. Pupynin, A.E. Ogorodnikov, Lett. Mater., 9 (1), 107 (2019). https://doi.org/10.22226/2410-35352019-1-107-112

[7] W. Jia, Q. Hong, H. Zhao, L. Li, D. Han, Mater. Sci. Eng. A, 606, 354 (2014). DOI: 10.1016/j.msea.2014.03.108 
[8] М.Б. Иванов, Ю.Р. Колобов, С.С. Манохин, Е.В. Голосов, Завод. лаб. Диагностика материалов, 78 (1-1), 43 (2012). [Пер. версия: 10.1134/S0020168513150065].

[9] E. Montoya, S. Bals, M.D. Rossell, D. Schryvers, G. Van Tendeloo, Microscopy Res. Techn., 70 (12), 1060 (2007). https://doi.org/10.1002/jemt.20514

[10] J. Mayer, L.A. Giannuzzi, T. Kamino, J. Michael, MRS Bull., 32 (5), 400 (2007). https://doi.org/10.1557/mrs2007.63

[11] R.M. Langford, M. Rogers, Micron, 39 (8), 1325 (2008). https://doi.org/10.1016/j.micron.2008.02.006

[12] Y.F. Guo, S. Xu, X.Z. Tang, Y.S. Wang, S. Yip, J. Appl. Phys., 115 (22), 224902 (2014). https://doi.org/10.1063/1.4881756 